\title{
El monasterio de San Prudencio de Monte Laturce (Siglos X-XII)
}

\author{
Francisco J. García Turza *
}

\section{INTRODUCCIÓN}

En la actualidad, en La Rioja se están sentando las bases para comenzar a estudiar seriamente aspectos muy diversos de la época medieval, gracias a las importantes publicaciones de carácter documental que se han realizado recientemente.

No obstante, la divulgación de estas fuentes no ha servido para dar a conocer algunos enclaves históricos de indudable importancia, como es el caso del monasterio de San Prudencio de Monte Laturce, centro neurálgico de este trabajo.

Precisamente llevado por estas lagunas textuales, me planteé recabar tanto la información conocida - muy escasa - como la inédita. Esta última proviene de un gran manuscrito de 394 folios, escrito en el año 1726 por el P. Gaspar Coronel (Historia del Real monasterio de San Prudencio con varias noticias y anexiones de la Historia General de España) ${ }^{1}$, monje del propio monasterio. Este autor transcribe, traduce y, en algunas ocasiones, interpreta y analiza aproximadamente ciento cin-

* Doctor en Historia Medieval.

1 En adelante, Coronel, Historia. 
cuenta cartas que abarcan los años 950 a $1545^{2}$. Esta colección diplomática se completa con varias fuentes impresas ${ }^{3}$.

Aprovechando estos fondos, en su mayor parte desconocidos, me introduzco en el estudio del monasterio de San Prudencio durante los siglos $\mathrm{x}$ al XII, para lo cual me sirvo de 60 cartas, repartidas cronológicamente de forma muy desigual (1 para el siglo $x, 16$ para el $x \mid$ y las restantes, 43, para el siglo $\mathrm{XI1)}$. A partir de estos testimonios trato de explicar la fundación y origen del cenobio, el papel que desempeñó en el proceso de repoblación y de reorganización de una extensa franja de terreno (área comprendida entre los ríos Leza, Jubera y Cidacos) y las relaciones que mantuvieron sus monjes con la monarquía (primero pamplonesa, luego castellana) y la nobleza local durante casi tres siglos. Dejo para un trabajo posterior el análisis de los aspectos socioeconómicos, jurídicos y espirituales.

El monasterio riojano de San Prudencio está ubicado en una hondonada del monte que le da su nombre, el Monte Laturce, entre las localidades de Clavijo y Leza del Río Leza, a una veintena de kilómetros de Logroño; un paraje inhóspito y agreste, que alberga las ruinas de la primitiva iglesia de finales del siglo XII, de tipo cisterciense, las de otra posterior del XVII y las del enorme caserío que las rodeaba.

${ }^{2}$ El que suscribe ha transcrito la mencionada colección documental (actualmente se encuentra en el Archivo del monasterio de Valvanera), que se completa, en unos cuantos casos, con algunos documentos originales localizados y con otras fuentes escritas. Como se hará referencia constante a aquélla y como en su publicación las cartas irán en idéntico orden, cada vez que se remita a la colección diplomática: se citará G. TURZA, San Prudencio.

3 J. González, El reino de Castilla en la época de Alfonso VIII, Madrid 1960, 3 vols.; A. C. DE Govantes, Diccionario Geográfico-Histórico de España. Comprende La Rioja o toda la Provincia y algunos pueblos de la de Burgos, Madrid 1846 (reeditado en Logroño 1986); C. LOPEZ DE SILANes y E. SÁINz RiPA, Colección Diplomática Calceatense. Archivo Catedral (1125-1397), Logroño 1985; J. A. LLORENTE, Noticias históricas de las tres provincias vascongadas, Madrid 1808, 4 vols.; I. Rodriguez R. DE LAMA, Colección Diplomática Medieval de La Rioja, Logroño 1976-1979, 3 vols.; E. SAinz RIPA, Colección Diplomática de las Colegiatas de Albelda y Logroño, Logroño 1981-1983, 3 vols.; A. UBIETo ARTETA, Cartulario de Albelda, Zaragoza 1981. 


\section{FUNDACIÓN Y PRIMERAS NOTICIAS}

Para el estudio del monasterio de San Prudencio, se ha dividido el proceso histórico en varias partes. La primera abarca desde el nacimiento del monasterio, que probablemente tuvo lugar hacia 925, hasta 950, año en el que la congregación pasa a depender del cenobio de San Martín de Albelda.

El silencio documental de este periodo me obliga a recurrir inexorablemente al proceso reconquistador que efectuaron los monarcas cristianos en los primeros años del siglo $x$, mediante el cual se podrá entender su nacimiento como centro religioso organizado (aunque muy posiblemente existiesen en sus proximidades pequeñas cédulas eremíticas mucho más antiguas, como ocurre en Albelda).

La Rioja formaba parte del territorio islámico gobernado por la familia de los Banu Qasi, cuya autoridad se extendia desde Nájera hasta Monzón, y era una de las rutas seguidas por éstos para atacar el reino leonés. Empujados por esta circunstancia, los reyes Sancho Garcés de Pamplona y Ordoño ll de León intentarán ocupar las tierras riojanas con el fin de cerrarles el paso. Ocuparon, en varias etapas, Nájera, Calahorra, Arnedo y Viguera.

La incorporación de estas tierras implicaba una rápida recuperación y fortificación de la vida cristiana en ellas. Ordoño restaura el monasterio de Santa Coloma, cerca de Tricio ${ }^{4}$, mientras que Sancho Garcés funda el de San Martín de Albelda ${ }^{5}$.

En linea con esta política real, es lógico pensar que el monasterio de San Prudencio, cercano a San Martín de Albelda, surgiese en esta coyuntura. Al igual que a esta abadia le correspondió reorganizar parte del valle del río Iregua, a San Prudencio se le encomendarian tareas repobladoras en el valle del río Leza.

4 J. E. Uranga Galdiano y F. Íniguez Almech, Arte Medieval Navarro, I, Pamplona 1971, págs. 20,40 y ss.

5 J. M. LACARRA, Historia Política del Reino de Navarra, desde sus origenes hasta su incorporación a Castilla, I, Pamplona 1972, pág. 119. 
Es un hecho comprobado que existía con anterioridad a 950, tal como se desprende del único documento que conservamos del siglo $x^{6}$. Gracias a él sabemos que el abad Adica y sus monjes se entregan a Dulquito, abad de San Martín de Albelda, con todas sus pertenencias.

La historiografía tradicional se ha encargado de explicar la fecha del nacimiento de San Prudencio, adelantándola en varios siglos. Como afirma fray Matheo de Anguiano en su obra ${ }^{7}$, sus orígenes están relacionados directamente con San Prudencio de Armentia, obispo de Tarazona en el siglo VI. Tras una vida de predicación y sacrificios, este personaje muere en Osma en un intento por solucionar ciertos problemas habidos entre el cabildo y el obispo de aquella ciudad. Ante el dilema de dónde debía ser enterrado, se determina colocar su cuerpo sobre una caballería de su propiedad; en el sitio elegido por el animal para pararse, alli debería ser sepultado. La bestia llegó hasta el Monte Laturce, lugar donde los clérigos que acompañaban al obispo fallecido levantaron la iglesia ${ }^{8}$, denominada en un principio San Vicente ${ }^{9}$.

Tras su fallecimiento, ocuparon el monasterio el arriba mencionado Adica y un grupo de monjes procedentes de las cercanías de Leza ${ }^{10}$.

${ }^{6}$ G. Turza, San Prudencio, núm. 1. Por su antigüedad e importancia es publicado por la totalidad de las colecciones diplomáticas recogidas en la nota 2.

Compendio Historial de la Provincia de La Rioja, de sus Santos y Milagrosos Santuarios, Madrid 1704 (nueva edición en Logroño, 1985), págs. 284-289.

${ }^{8}$ Véase A. YEPES, Crónica General de la Orden de San Benito. Estudio preliminar y edición de J. Pérez de Urbel. Madrid 1969, vol. II, págs. 316-317.

${ }^{9}$ Así se desprende de G. Turza, San Prudencio, núm. 1, en donde se indica claramente que Monte Laturce albergaba la "ecclesiam Sancti Vicentii et domini Prudentii vasilicam". A partir de los términos "Sancti» y "domini" los historiadores tradicionales entran en una controversia sobre la antigüedad e importancia de la figura de Prudencio, que les llevará a escribir ríos de tinta, pero con unos resultados poco esclarecedores. En opinión de una parte de aquellos estudiosos, encabezados por A. YEPES (Crónica, II, págs. 318319), a Prudencio no se le denominaba "Sancti" sino "domini" o "venerable", porque hacia pocos años que había muerto. El apelativo "Sancto" implicaba lejania en el tiempo. Por el contrario, G. Coronel (Historia, fols. 24, 85 y ss.), defendía la antigüedad de Prudencio; no duda en llevarlo hasta el siglo VII, pero de una forma vaga e imprecisa. En cualquier caso, los instrumentos escritos revelan a las claras que los monjes que pasan a Albelda veneraban de forma especial a San Vicente: "prefatis Sancti Vincentii fratribus" (G. TuRzA, San Frudencio, núm. 1).

Según G. CORONEl (Historia, fol. 28r), se pasó a denominar monasterio de San Prudencio a partir de 1025 tal como se desprende de un privilegio de Sancho III el Mayor, que no cita. Por mi parte, localizo la primera mención al monasterio entre 1011-1021 en una interpolación de un documento del año 880 (A. J. MARTIN DUQUe, Documentación medieval de Leire (siglos $\mathrm{I}$ a XII), Pamplona 1983, núm. 4).

10 A. YEPES, Crónica General, II, pág. 317. 


\section{ANEXIÓN AL MONASTERIO DE SAN MARTIN DE ALBELDA}

La segunda parte de la evolución histórica de la abadia abarca la absorción por el monasterio de San Martín de Albelda, que va desde el año $950^{11}$ hasta $1058^{12}$.

Hacia 923, La Rioja Alta podía considerarse definitivamente ganada para los cristianos. Mientras tanto, Calahorra, que en un principio habia quedado incorporada a los dominios de Sancho Garcés I, pronto se perdió, así como el territorio riojano comprendido hasta el valle del río Leza ${ }^{13}$.

La ubicación del monasterio, eminentemente fronteriza, hace que quede expuesto a cualquier avance musulmán. Esta situación propicia un ambiente de inseguridad, que se traduce en pobreza y abandono. Así las cosas, los monjes toman una medida determinante: su paso al monasterio de San Martín de Albelda.

Este hecho se constata documentalmente a través de un texto perfectamente conocido. En 950 el abad del cenobio, Adica, acompañado de los miembros de su congregación: los hermanos Cristóbal, Ordoño, Sarracino, Dato, Esteban y Rapinato, y de varios obispos y abades ${ }^{14}$, se encomiendan y entregan al abad de Albelda. Aportan como patrimonio, entre otros bienes, «la ecclesiam Sancti Vicentii et domini Prudentii vasilicam".

Tras el abad Adica, G. Coronel ${ }^{15}$ sitúa a Abibi o Bibas; como su predecesor, fue enterrado en Laturce. Hacia 972 le sucede otro abad del mismo nombre ${ }^{16}$. Rapinato, uno de los siete monjes que junto a Adica

" G. Turza, San Prudencio, núm. 1.

12 Ibidem, núm. 5.

13 A. Ubieto ARTETA, Atlas histórico. Cómo se formó España. Valencia 1970, pág. 50

14 Firman como testigos Tudemiro, obispo de Nájera; Dulquito, abad de Albelda; Diego, abad "Sobiensi»; Munio, abad de Santa Coloma; Esteban, abad de San Millán; y Belasco, abad de Cirueña, que venían de Arreso (RESA, despoblado frente a Murillo de Calahorra) de celebrar el aniversario de Sancho Garcés 1, padre de García Sánchez I (G. TuRzA, San Prudencio, núm. 1).

15 Historia, fol. 26v.

16 Ibidem. Para A. YePes (Crónica General, II, p. 325), se trataria de un solo personaje. 
pasaron a Albelda ${ }^{17}$, fue elegido como abad hacia 985 . A comienzos del siglo XI encontramos como abad de San Prudencio a "domino Galindo" ${ }^{18}$; en 1025, G. Coronel localiza a Tello de Jalón al frente de la abadía en un privilegio del monarca Sancho III el Mayor, en el que concede al monasterio todas las décimas del Valle de Arnedo ${ }^{19}$. Según este escritor, se mantuvo al frente de su cargo durante un largo período, ya que veinte años más tarde recibe una donación de doña Mencia, hija natural del monarca García el de Nájera ${ }^{20}$. A su muerte, resultó elegido Martín, con el que San Prudencio escapa del dominio albeldense.

Los monjes, ¿abandonaron el monte Laturce y cambiaron su residencia por la de Albelda o, por el contrario, residieron permanentemente en su monasterio bajo la observancia de San Martín? Consta documentalmente que la entrega de bienes efectuada al cenobio albeldense se realizó por varios motivos: para que nunca faltasen personas que sirvieran alli a la oblación y sacrificio, para mantener iluminada la iglesia y, por último, para poder costear los gastos de sustento que ocasionara la congregación a Albelda ${ }^{21}$. De aquí se concluye que el monasterio de San Prudencio nunca llegó a abandonarse, al menos de forma total. Quizá, cuando el peligro musulmán resultaba más apremiante, los monjes pasaban a vivir temporalmente a Albelda, mientras que en épocas de mayor tranquilidad la abadía mantenía una dinámica estable, claro que siempre favorecida por el apoyo y la protección de San Martín.

Por el contrario, conforme La Rioja Baja va quedando asegurada en manos cristianas, se aprecia una cierta autonomía monástica en relación a San Martín de Albelda y un paulatino crecimiento dominical, de tal modo que el abad del monasterio aparece acompañando a los abades de las casas riojanas más importantes ${ }^{22}$ y dispone de prerrogativas para admitir donaciones ${ }^{23}$, otorgar escrituras, erigir sepulcros, etc. ${ }^{24}$.

17 G. CORONEL, Historia, fol. $27 \mathrm{v}$.

18 A. J. Martin Duque, Documentación medieval de Leire, núm. 4.

${ }^{19}$ A. YEPES (Crónica, II, pág. 325) sitúa entre 1057-1065 su etapa de gobierno.

${ }^{20}$ Historia, fol. 27v-29v.

21 G. Turza, San Prudencio, núm. 1.

22. Hacia 1011-1021, recogemos como confirmante el abad de San Prudencio "dompno Galindo", que aparece en compañia, entre otros, del abad Ferrucio de San Millán de la Cogolla y del obispo Garcia de Albelda (A. J. Martin DuQue, Documentación medieval de Leire, núm. 4).

${ }^{23}$ En 1057, Mencia, hija del rey García de Nájera, dona a San Prudencio los palacios que poseía en la villa de Leza y unas heredades en Rio Leza (G. TuRzA, San Prudencio, núm. 4).

${ }^{24}$ G. Coronel, Historia, fol. 53. 
A pesar de la pobreza textual, no podemos olvidarnos de un tema fundamental, del que nada sabemos: la observancia regular. Los religiosos de San Prudencio, ¿eran monjes benedictinos, clérigos regulares, etc.? Los instrumentos escritos no reflejan ninguna luz sobre el caso, tanto durante la andadura en solitario de la abadía de Laturce como en su posterior paso a Albelda. Nos consta que en el momento de su adscripción o en el inmediatamente posterior, aquella abadia tomó la regla de la que a partir de mediados del siglo $x$ iba a ser su casa madre; pero las fuentes tampoco nos indican con certidumbre, a pesar de las numerosas menciones documentales existentes durante el siglo $x^{25}$, a qué observancia pertenecian los monjes de Albelda.

\section{EL SEÑORÍO DE LOS CAMEROS}

Esta nueva etapa comprende el patronato del monasterio de San Prudencio por parte de los señores de los Cameros. Se extiende desde mediados del siglo $\mathrm{xi}$, momento a partir del cual la abadia se independiza de San Martín de Albelda, hasta 1181, año en que San Prudencio acepta los usos y la obediencia cistercienses y se libera de la protección señorial.

El rey García el de Nájera recupera Calahorra en 1045, y con este importante enclave, situado entre Navarra, Aragón y Castilla, se incorpora un extenso marco geográfico, que muy posiblemente se extendiese aproximadamente hasta el río Leza.

Para el gobierno de estas tierras los monarcas sitúan a su frente a personas importantes de la corte, los "tenentes", que procurarán la defensa de los territorios reconquistados y dirigirán la repoblación y reorganización eclesiástica de la zona recuperada. No es arriesgado pensar

${ }^{25}$ Dudosas en su totalidad. Sobre este aspecto, véase A. LiNAGE CONDE, Los origenes del monacato benedictino en la Península lbérica, II. León 1973, págs. 662-669. El mismo autor ( En torno a la benedictización. La recepción de la Regla de San Benito en el monacato de la península ibérica a través de Leyre y aledaños", en Príncipe de Viana, 174 (1985), págs. 87-88) afirma que habrá que llegar al reinado de García el de Nájera para encontrar, en 1040 y en Leyre, la primera referencia incuestionable a la Regla Benedictina. 
que aquéllos formaban parte de la nobleza surgida con la reconquista de nuevas tierras.

A mediados del siglo XI, el monarca Garcia el de Nájera otorga a Fortún Ochoa, señor de Viguera ${ }^{26}$, el gobierno del valle de Arnedo, los Cameros $^{27}$, la comarca de Cantabria ${ }^{28}$, etc., con el firme propósito de asegurar la zona y recuperar en el aspecto humano, religioso y económico-social el área recientemente ganada a los musulmanes. Para facilitar estas tareas, el rey pamplonés le concede en donación varias heredades en los lugares de Nalda, Leza y Jubera.

Fortún Ochoa estuvo casado con una hija del monarca García el de Nájera, doña Mencia ${ }^{29}$, en cuya compañía fue enterrado en el interior de San Prudencio ${ }^{30}$, cenobio por el que debieron sentir desde fechas tempranas una gran devoción ${ }^{31}$.

A su muerte, hacia 1057, sus cinco hijos se repartieron el gobierno de los territorios: Íñigo heredó el señorío de Arnedo; Lope el de Calahorra; Sancho el de Huarte; Arnar el de Cantabria; y Jimeno, los Cameros y Viguera.

En consonancia total con aquellos propósitos reorganizativos y con el fin último de llevarlos a buen término, Jimeno Fortúnez, sucesor de Fortún Ochoa, acude, como tantas otras veces lo habian hecho las clases dominantes, a los monasterios. Para ello, el 19 de marzo de $1058^{32}$

${ }^{26}$ A. Ubieto, Cartulario de San Millán de la Cogolla (759-1076), Valencia 1976, núm. 259; e I. Rodriguez R. DE LAMA, Colección, núm. 4. Como antecesores suyos, E. Oca y Merino (E. Oca y Merino, Recuerdos de Cameros. Apuntes de Geografía e Historia de la región, y de los hijos distinguidos de la misma, Logroño 1913, pág. 30), sitúa a Sancho Fernández de Tejada, su abuelo, persona muy cercana al monarca Ramiro que participó al lado de éste en la batalla de Clavijo y más tarde fue nombrado "Capitán General" de la frontera de los Cameros; y a su padre, Jimeno Sáenz de Tejada (lbidem, pág. 47).

${ }_{27}$ G. Coronel, Historia, fol. 28v. La primera mención del señorio de los Cameros data de 1063, cuando Jimeno Fortúnez aparece como testigo en una carta de donación real en favor del monasterio de San Prudencio (G. Turza, San Prudencio, núm. 7); por su parte, I. Rodriguez R. DE LAMA (Colección, I, pág. 364), retrasa la fecha hasta 1154-1158 y afirma que Diego Jiménez y su familia son los iniciadores del linaje de los Cameros.

26 A. Ubieto ARteta, Cartulario, núm. 47.

29 En opinión de E. OCA y MERINo (Recuerdos de Cameros, pág. 47), fue mujer de Jimeno Fortúnez uno de sus sucesores.

30 G. Turza, San Prudencio, núm. 7.

${ }^{31}$ Fruto de ella, en 1057 Mencia dona a San Prudencio los palacios que poseia en la villa de Leza y las heredades de Río Leza (Ibidem, núm. 4).

32 T. Marín (Diccionario de Historia Eclesiástica de España, III, pág. 1657) sitúa, erróneamente, esta operación de intercambio el 13 de las kalendas de la era de 1067, año 1029. 
cambia al cenobio de San Martín de Albelda el de San Miguel de Yécora - Bihurco, de su propiedad ${ }^{33}$, por el de San Prudencio de Monte Laturce ${ }^{34}$, operación de canje confirmada unos meses más tarde ${ }^{35}$. Además, Jimeno otorgaba al monasterio el carácter de panteón familiar ${ }^{36}$.

Como patrón y protector de la abadía, Jimeno procura dotarla de los medios necesarios para emprender tareas de carácter social, religioso y de reorganización de las nuevas tierras. Las numerosas donaciones reales y aquellas otras protagonizadas por miembros de su linaje así lo apuntan, tratando de revitalizar primero los propios centros donados y, más tarde, a partir de ellos mismos, el de sus territorios próximos.

Un hermano de Jimeno, Sancho, dona a San Prudencio el monasterio de San Miguel de Arnedo en $1063^{37}$; el monarca Sancho Garcés IV, a petición de Jimeno, los de San Agustín y San Saturnino de Pavía en $1065^{38}$, ¿cercanos a Viguera?; el rnismo monarca dona en 1068 la "casa" de Santa María de Arnedillo ${ }^{39}$. Jimeno Fortúnez entrega la iglesia de San Esteban de Torrijas ${ }^{40}$ y sus heredades hasta el rio Ebro ${ }^{41}$.

En resumen, durante el largo gobierno de Jimeno Fortúnez, el dominio adquire una importante expansión territorial a través de tres áreas perfectamente diferenciadas: los valles de los ríos Leza, Jubera y Cidacos.

Esta gestión de apoyo al monasterio sufrió un paréntesis a la muerte de Sancho Garcés IV, que se prolongará durante la división del reino de

${ }^{33}$ Quizá por intercesión de Mencia y Fortún (G. CORONEL, Historia, fol. 30v), su hijo Sancho Fortúnez consiguió, entre otros bienes, la cesión de este monasterio en 1057, a cambio de un caballo y dos azores (G. Turza, San Prudencio, núm. 3).

${ }^{4}$ Ibidem, núm. 5.

${ }^{35}$ Ibidem, núm. 6.

${ }^{36}$ Cuando Sancho Fortúnez, hermano del patrón Jimeno Fortúnez, dona a San Prudencio la iglesia de San Miguel de Arnedo, afirma hacerlo «para remedio de mi alma y por las animas de mi padre y de mi madre, de mis hermanos y hermanas que estan sepultados en aquel lugar, para donde yo tambien ofrezco mi cuerpo y mi alma" (lbidem, núm. 7).

37 lbidem.

38 Ibidem, núm. 9. Estos últimos son cambiados ese mismo año a Albelda por el monasterio de Pampaneto, en tierras de Ocón, el lugar de Villanueva, las iglesias de San Pelayo de Leza y San Andrés y varias heredades en Trevijano (Ibidem, núm. 10).

${ }^{39}$ Ibidem, núm. 11

40 Torrijas, antigua aldea, luego despoblado, dentro del término municipal de Logroño (P. Gonzalez GonzAlez, Noticias históricas de los despoblados riojanos). Logroño, Biblioteca del IER, M/391

${ }^{4}$ G. Turza, San Prudencio, núm. 12. 


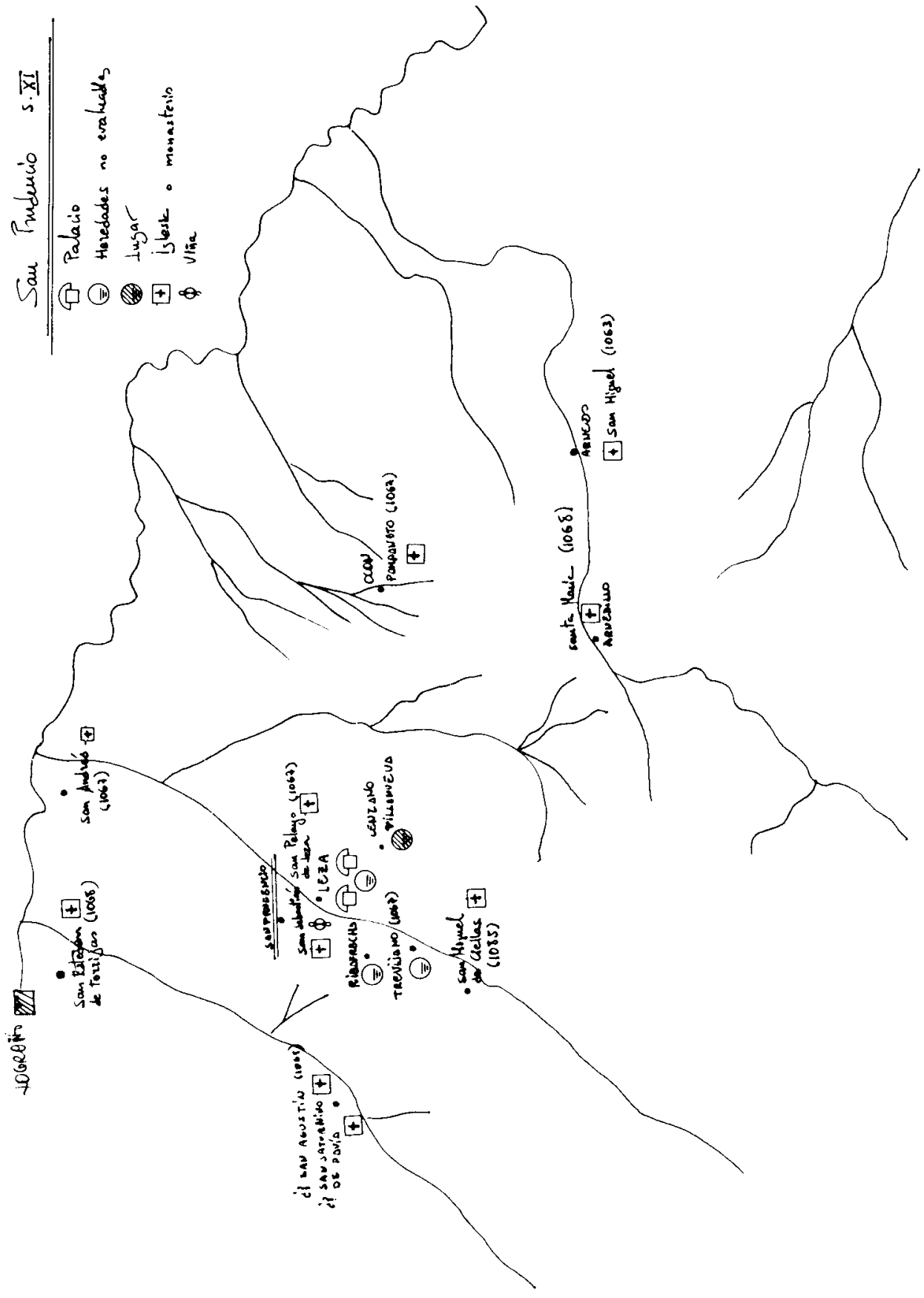


Pamplona entre Sancho Ramírez de Aragón y Alfonso VI de Castilla y la ocupación definitiva de La Rioja por parte del segundo.

A Jimeno Fortúnez le sucede su hijo Íñigo Jiménez. Como aquél, mantiene una política expansionista, basada en parte en la ocupación de iglesias o pequeños monasterios, en su mayoría deshabitados. Hacia 1085, don Cite dona a San Prudencio el monasterio "propio" de San Miguel de Ciellas, casa situada entre Soto de Cameros y Terroba $^{42}$; En 1097 participa, junto al abad de San Prudencio, Martín, en un intercambio con San Martín de Albelda de la iglesia de San Sebastián y una viña, ambas cercanas a Laturce. A cambio, aquellos conceden varias viñas ${ }^{43}$. En 1102 Pedro, obispo de Nájera, a petición de Íñigo, dona a San Prudencio las iglesias de Santa Eulalia de Miromnes y la de San Saturnino de Salas, en el valle de Arnedo, con la condición de que un tercio de los diezmos que les correspondian en concepto de parroquias recayesen en las arcas del obispado ${ }^{44}$.

Estas aportaciones van a posibilitar la terminación de parte de las obras que se realizaban en el interior del monasterio de San Prudencio y que empezó, años antes, Jimeno Fortúnez ${ }^{45}$. Entre ellas sobresale una capilla para el enterramiento de Íñigo Jiménez y su esposa María González ${ }^{46}$.

El apoyo de los patronos a los monjes resulta firme y comprometido. En 1109, Iñigo Jiménez y su mujer hacen legación testamentaria de sus bienes en favor de los monjes, de tal modo que a su muerte pasarian a Laturce la gran mayoría de sus pertenencias ${ }^{47}$.

Al fallecimiento de Alfonso VI, y tras el matrimonio de su hija Urraca con Alfonso I el Batallador, se desata una gran incertidumbre política, que lleva a Iñigo Jiménez, al igual que a una parte importante de la nobleza fronteriza, a tomar partido en favor del monarca aragonés. Muy pronto vemos a Iñigo alternar el señorío de los Cameros y Arnedo con la tenencia de Caiahorra ${ }^{48}$; del mismo modo se ve favorecido en 1112 por la

42 lbidem, núm. 16.

43 Ibidem, núm. 17.

44 Ibidem, núm. 18.

45 Ibidem.

46 Ibidem, núm. 19.

${ }^{47}$ Ibidem.

48 Documentado en 1110 (F. J. GARCIA TuRZA, Documentación medieval del monasterio de Valvanera (siglos XI-XIII). Zaragoza 1985, núms. 202 y 205). según A. UBIETO ARTETA (Notas sobre los "tenentes", pág. 225), fue el séptimo tenente de la ciudad. 
entrega real de las villas de Muro Frecho, Villa Rubia, Villar de Hicera, Villar de Colubras, Villar Sotelo y Grábalos ${ }^{49}$.

Las características de esta situación pudieron determinar el silencio documental que observamos en los años siguientes. No sabemos qué suerte pudo correr Iñigo Jiménez ni si se mantuvo firme como tenente de Alfonso I. En 1120, en una carta de donación a San Prudencio (en la que Mencia Jiménez, posiblemente hermana de Iñigo, aparece entregando a la abadía una heredad en Villamediana), se lee que Lope López accede a la tenencia de Calahorra ${ }^{50}$ y Lope Yáñez al señorio de Arnedo ${ }^{51}$. Un año más tarde, de nuevo Mencia Jiménez dona a San Prudencio la villa de Luezas, una heredad en Nalda y todos los bienes muebles que se hallasen en su poder en el momento de su fallecimiento ${ }^{52}$.

A la muerte de Alfonso I el Batallador, La Rioja pasó a poder directo de Alfonso VII. Este se apresuró a castellanizar el territorio, cediendo parte de sus bienes entre las familias nobles y entre los monasterios. De entre los primeros, en 1144 Jimeno íñiguez, señor de los Cameros, hijo mayor de Iñigo Jiménez y María González, recibe en recompensa del rey (por los servicios prestados y «por la espada llamada Bastun que me ha dado" (habla el monarca]), la villa de Robres y el monte llamado La Santa, así como todas sus posesiones en Nalda ${ }^{53}$.

Pero no solamente salieron beneficiados los señores. En 1145 la abadía recibe de Alfonso VII la villa de Lagunilla ${ }^{54}$, a cambio de las heredades que San Prudencio poseia desde el puente de Logroño hasta Santa María de Munilla de los Huertos y las heredades de Valdegrua ${ }^{55}$; dos años más tarde, los monjes reciben del monarca la iglesia de San Vicente de Yangüela, cercana a la población de Villamediana, una heredad en Varea y un canal cercano al puente de Logroño ${ }^{56}$.

49 G. Turza, San Prudencio, núm. 20.

so Ibidem, núm. 21. A. UBIETO ARTETA (Notas sobre los "tenentes", pág. 226) lo sitúa cronológicamente entre 1114 y 1124.

${ }^{51}$ G. Turza, San Prudencio, núm. 21.

52 lbidem, núm. 22.

53 lbidem, núm. 23.

54 Su importancia queda reflejada a través de los límites, que se expresan: «ita inquam concambio cum onmibus suis terminis sicut partitur cum Murello, et cum Leza, et cum Villa nova et cum la Santa, et cum Robres et cum Ocon, et cum Santo Martino de Barvazana" (Ibidem, núm. 24).

55 Ibidem.

56 Ibidem, núm. 25. 
Hasta mediados del siglo xII, la expansión del monasterio de San Prudencio había girado en torno al Somontano y la Sierra, pero a partir de ese momento, coincidiendo con el nombramiento de Pedro Jiménez, hijo de Jimeno íñiguez ${ }^{57}$, como señor de los Cameros y de Logroño, el monarca Alfonso VII, para reafirmarlo en el cargo al frente de la tenencia de esta población y de la zona circundante, le premia, aunque indirectamente a través del monasterio del que era patrono, con las donaciones antedichas en las proximidades del Ebro $y$ en las cercanías de Logroño $^{58}$.

\section{SANTA MARIA DE RUTE}

Directamente entroncada con San Prudencio desde 1181, miembros del linaje de los Cameros fundan una nueva abadia, Santa María de Rute (sobre unas ruinas, al parecer visigóticas) ${ }^{59}$, que se muestra como piedra de toque desde la que sería posible efectuar las tareas reorganizadoras en el valle del Jubera.

El nacimiento de este centro religioso está directamente vinculado con los problemas suscitados entre los reinos de Navarra y Castilla, precisamente durante la minoría del rey Alfonso VIII. Entre octubre de 1162 y marzo de 1163, los navarros ocuparon diversas plazas de La Rioja, la más importante Logroño; al sur del Ebro fueron tomadas Ausejo, Resa, Autol, Quel y Ocón ${ }^{60}$. Queda fuera de estos dominios la fortaleza defensiva de Clavijo y, por lo tanto, el monasterio de San Prudencio ${ }^{61}$, del que, durante varios años, no quedan testimonios escritos conocidos.

Carecemos de cualquier argumento para explicar esta laguna textual. Podemos pensar que se trata de una respuesta al languidecimiento sufrido por la congregación precisterciense, que propiciará el olvido tempo-

${ }^{57}$ Merino de Alfonso VII, y de María González (¿de Lara?) (J. GonzALEz, El reino de Castilla, págs. 317 y 318 ).

${ }^{58}$ G. Turza, San Prudencio, núm. 21.

${ }^{9}$ M. A. MARTin BUENO, "Novedades de Arqueologia Medieval Riojana", en Miscelánea de Arqueologia Riojana. Logroño 1973, págs. 197-200.

${ }_{60}$ J. M. LacarRa, Historia del Reino de Navarra, págs. 215-216.

61 Véase J. Gonzalez, El reino de Castilla, págs. 785 y ss. 
ral del monasterio y el traspaso de las responsabilidades monásticas y socioeconómicas a Santa María de Rute, situado en territorio fronterizo.

Para contrarrestar el empeño del rey navarro Sancho VI por fortificar su posición en esta zona, el señor Pedro Jiménez (sucesor de Jimeno Íniguez), partidario del monarca castellano Alfonso VIII, dona a la abadia cisterciense de Santa María de Sacramenia, en la actual provincia de Segovia, tierras y bienes suficientes para la construcción de un monasterio, precisamente en el centro de los territorios conquistados en La Rioja Baja (cerca del río Jubera y no lejos de Ventas Blancas), y para asegurar la vida de la comunidad ${ }^{62}$. Este nuevo cenobio se coloca bajo la advocación de Santa María.

No sabemos porqué el centro segoviano fue el encargado de organizar y formar el cenobio rutense y no otro más cercano. Pudiera ser que, debido al favor real de que gozó Sacramenia desde su fundación y con posterioridad a eila, el señor de los Cameros se viese obligado a hacer depender la abadía de dicha casa, a la vez que castellanizaba su futura área de expansión.

El abad de Sacramenia, don Pedro, manda incorporarse rápidamente a una docena de monjes, tal como era costumbre, a cuyo frente sitúa a Raimundo ${ }^{63}$. Dado que en su origen aquéllos procedian de Scala DeiMorimond ${ }^{64}$, es lógico pensar que Santa María de Rute perteneciese a la misma filiación cisterciense.

Una vez alcanzado el proceso fundacional del abadengo, se hacia necesario mejorar e, incluso, como opina G. Coronel, ampliar ${ }^{65}$ el antiguo caserío monástico: en 1165, el señor Pedro López de Lagunilla dona a Santa. María una pieza, la de Blasquillo, para construir en ella las dependencias monásticas ${ }^{66}$. A continuación, regulan las relaciones con el obispado: este mismo año, el abad Raimundo, al ser promovido a su

62. G. Turza, San Prudencio, núm. 27.

${ }^{63}$ G. Coronel, Historia, fol. 79v. Según A. Yepes (Crónica, III, 455-456), los monjes cedidos en un principio por el abad Pedro fueron dos o tres.

${ }^{64}$ J. Perez-Embid, El Cister en Castilla y León. Monacato y dominios rurales (siglos XIIxv). Salamanca 1986, pág. 271.

${ }_{65}$ Historia, fol. $79 \mathrm{v}$.

66 G. Turza, San Prudencio, núm. 28. 
dignidad, presta obediencia y sumisión al obispo de Calahorra don Rodrigo y a su iglesia ${ }^{67}$.

Superada la minoría de edad, Alfonso VIII, consciente de la importancia que para la seguridad de Castilla tenía la fijación de sus fronteras, y en un intento por recuperar La Rioja, concede su apoyo al nuevo monasterio de Santa María de Rute. Esta circunstancia no debemos juzgarla como un hecho aislado, sino que habrá que enmarcarla dentro de una nueva floración cisterciense ${ }^{68}$, que se traduce en la donación real a Rute de tres sernas en el término de Ocón ${ }^{69}$.

La posterior firma de una paz transitoria (por 10 años) entre el castellano Alfonso VIII y el navarro Sancho VI en Fitero, en 1167 conducirá a un corto período de estabilidad, muy fructífero para el monasterio. Siguiendo el ejemplo del monarca castellano, se producen varias donaciones: en 1167, las hermanas Sancha, Teresa y Urraca Jiménez entregan a Santa María de Rute varias suertes del cañal (¿canal?) llamado Picadonas, junto al puente de Logroño ${ }^{70}$; en 1170 Urraca y su hija Elvira donan una pieza junto al mismo monasterio ${ }^{71}$.

Por su parte, el monarca navarro Sancho IV, acaso consciente del peligro que supondría para sus territorios que el monasterio y su área de influencia cayese en manos castellanas, o bien porque el patrón y los monjes de Rute estimasen más ventajosa la protección del navarro ${ }^{72}$, se apresura a confirmarles un importante privilegio, por el que tomaba bajo su custodia todas las posesiones de la abadía y concedía a sus ganados el derecho a pastar libremente por su reino ${ }^{73}$.

Igualmente grande era el interés del señorío camerano por asegurar y acrecentar el dominio monástico. En 1170 figuraba como tenente de los Cameros Diego Jiménez ${ }^{74}$, casado con Guiomar Fernández de

${ }^{67}$ Ibidem, núm. 29.

68 J. GonzÁlez, El Reino de Castilla, págs. 510 y ss.

69 G. Turza, San Prudencio, núm. 30.

70 lbidem, núms. 31, 32 y 33.

71 lbidem, núm. 35.

72 Postura esta última dudosa. En 1170 el señor de los Cameros, Diego Jiménez, y el de Jubera, su hermano Pedro, aparecen bajo la obediencia de Alfonso VIII (Ibidem, núm. 35).

${ }^{73}$ Ibidem, núm. 34

${ }^{74}$ Y de Calahorra, a partir de 1185 (A. UBieto, Notas sobre los "Tenentes", pág. 230). 
Traba ${ }^{75}$; su hermano Pedro dominaba Jubera ${ }^{76}$. Se documentan otros miembros de su familia realizando donaciones: en 1172 don Sancho Jiménez entrega una pieza en el término de Murillo ${ }^{77}$ y Pedro Jiménez de los Cameros concede una casa en Jubera ${ }^{78}$.

La importancia alcanzada por la abadía en sus escasos años de vida lleva en ocasiones a ciertas personas, de estrato social alto, a entregarse a Santa María como "familiares". Tal es el caso del señor Sancho Jiménez y su mujer doña Maria, que a cambio ceden a Rute la mitad de sus bienes ${ }^{79}$; de Domingo Manco y su mujer Toda, que donan varias tierras ${ }^{80}$; de Lope Aznárez de Lagunilla, que solicita ser acogido por los monjes aquejado por una enfermedad. A cambio, este último haría entrega de su hacienda ${ }^{81}$.

La tregua firmada en 1167 por Sancho VI y Alfonso VIII se rompe a finales de 1172, posiblemente por la complicidad que mostraron algunos señores con el castellano ${ }^{82}$, a los que premió con importantes concesiones, siempre situadas en las cercanías de la frontera navarro-castellana.

El señor de los Cameros, no tanto por la lealtad mostrada hacia Alfonso VIII, con la que éste contó siempre, sino en recompensa por su ayuda, recibe del monarca en 1173 la villa de Herce, próxima a Arnedo ${ }^{83}$.

El monarca castellano, en alianza con Aragón, efectuó varias expediciones para recuperar La Rioja, en algunas de las cuales llegó hasta Pamplona ${ }^{84}$. Como consecuencia de la realizada en el verano de 1175, entrega a Nájera, tras su conquista, la villa de Nestares, población cercana a Torrecilla en Cameros ${ }^{85}$. Precisamente en su recuperación inter-

${ }^{75}$ E. Oca y Merino, Recuerdos de Cameros, pág. 64.

${ }^{76}$ G. Turza, San Prudencio, núm. 35.

77 Ibidem.

78 Ibidem, núm. 38.

79 lbidem, núm. 37.

${ }^{80}$ Ibidem, núm. 39.

${ }^{81}$ Ibidem, núm. 40.

82 J. GonZÁLEZ, EI reino de Castilla, pág. 797.

${ }^{33}$ Ibidem, núm. 180.

${ }^{84} \mathrm{lbidem}$, núm. 798.

${ }^{85}$ lbidem, núm. 801. 
vino el señor de los Cameros Diego Jiménez, que por esta causa recibió de los monjes de Santa María de Nájera la villa de Treguajantes ${ }^{86}$.

Por fin, la campaña que Alfonso VIII efectuó en 1176 dio como resultado la ocupación del castillo de Leguín, que pareció definitiva a Sancho VI. Este y Alfonso VIII decidieron someter sus diferencias al arbitraje de Enrique II de Inglaterra; pero no será hasta el 15 de abril de 1179 cuando se ponga fin a las cuestiones territoriales.

El 25 de agosto de 1176, tras la firma de la paz, se acuerda que Arnedo pase a poder de Diego Jiménez ${ }^{87}$; en 1185 recibe el castillo de Yémeda, 10 yugadas de heredad en Azafra, aldea de Huete, y el valle del Manzano en Belvis ${ }^{88}$; dos años más tarde, una vez firmado un tratado de paz entre el rey castellano y el aragonés, recibirá los castillos de Ágreda, Cervera y Aguilar $^{89}$.

Con el propósito de afianzar los territorios fronterizos, Diego Jiménez concede a Alfonso VIII los castillos de Portilla, Siero, Buradón, Alcazaba, Peñalba, Alio, Aguilar, Entreoteros y Orcejón ${ }^{90}$, a cambio de las villas de Maqueda, Arlanzón, Bozigas, Huércanos y Orógola ${ }^{91}$; más tarde, en 1184, las localidades de Arlanzón, Bozigas y Villa Cruz vuelven a poder del rey a cambio del castillo de Enciso, que pasa a manos de Diego Jiménez ${ }^{92}$.

En 1188 éste presta juramento en un tratado que tiene lugar entre Alfonso VIII y Federico I de Alemania, por el que se acuerda el matrimonio de sus hijos Berenguela y Conrado ${ }^{93}$.

Para A. Ubieto, Diego Jiménez murió con anterioridad a $1197^{94}$, aunque considera la posibilidad de que detentaría la tenencia de Calahorra hasta la fecha de su fallecimiento.

86 Aldea de Soto de Cameros. Esta donación fue revocada en 1179 (1. Rooriguez R. DE Lama, Colección Diplomática, núm. 271).

87 J. GONZALEZ, El reino de Castilla, núm. 267.

${ }^{88}$ Ibidem, núm. 427.

${ }^{89}$ Ibidem.

${ }^{90}$ A. C. DE Govantes (Diccionario Geográfico, núm. 19, pág. 283) recoge también la variante de Orsello.

${ }_{91}$ G. TURza, San Prudencio, núm. 42.

${ }_{92}$ Ibidem, núm. 51.

93 J. GonzÁlez, El reino de Castilla, núm. 499.

${ }^{94}$ Notas sobre los "Tenentes", pág. 230. No obstante, A. C. DE Govantes (Diccionario Geográfico, núm. 19) transcribe textualmente unos versos copiados en la tapa del sepulcro de Diego Jiménez, en los que se afirma que falleció el 29 de octubre de 1187. 
FRANCISCO J. GARCIA TURZA

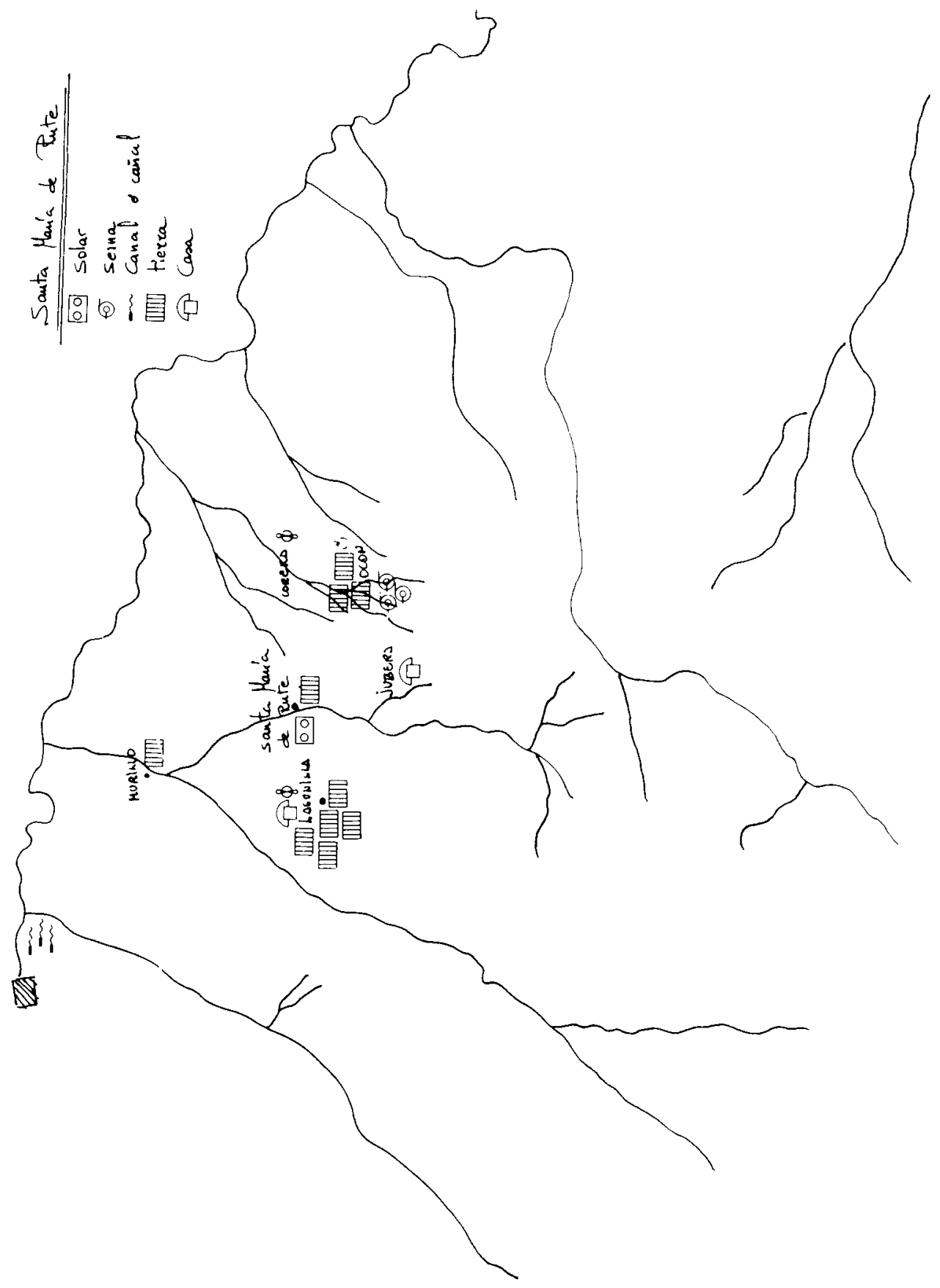

154 


\section{SAN PRUDENCIO: MONASTERIO CISTERCIENSE}

Coincidiendo con el restablecimiento de las fronteras entre Navarra y Castilla, las fuentes escritas vuelven a referirse con generosidad al monasterio de San Prudencio, en esta ocasión en estrecha relación con el devenir de Santa María de Rute.

Al rápido ascenso de esta abadía durante la etapa de enfrentamientos entre los reyes Alfonso VIII y Sancho VI, va a suceder su precipitada desaparición. Entre las causas, nunca apuntadas por los textos contemporáneos, cabe indicar que los motivos que llevaron a los señores de los Cameros a la fundación del centro rutense habían desaparecido y con ellos la existencia del propio centro religioso. Pasado el peligro y establecido el poder castellano hasta el río Ebro, los patronos encuentran más factible llevar a cabo las tareas de reorganización del territorio desde el propio cenobio de San Prudencio.

El 20 de agosto de 1181, Diego Jiménez y su mujer doña Guiomar donan a la orden del Cister y al monasterio de Santa María de Rute, con su abad Lamberto a la cabeza, el de San Prudencio, pero con la condición de que la congregación de Rute pasase a ocupar la abadía de Monte Laturce.

Este cambio de residencia podía responder a la simultaneidad de dos situaciones muy diferentes. La relajación de los monjes de San Prudencio les llevó a la pérdida de una parte importante de su significación religiosa, justo en el momento en que sus patronos estaban volcados en el reparto de poder político resultante de las fricciones navarro-castellanas, por lo que la comunidad monástica sufre un abandono temporal. La superación de estos factores adversos y la circunstancia de que San Prudencio habría sido durante muchos años lugar de enterramiento del linaje de los Cameros, son motivos suficientes para que este centro religioso vuelva a revitalizarse, iniciando una nueva andadura.

Cuenta la historiografía tradicional que el paso se produjo sin hostilidades entre ambas congregaciones. Lamberto y sus monjes llegaron a Laturce 19 años después de haber comenzado las obras de edificación del monasterio de Santa María de Rute, llevando consigo los cuerpos del patrón Pedro Jiménez y del abad Raimundo para ser enterrados en San Prudencio. Por su parte, el abad Ínigo y su comunidad se pusieron bajo 
las órdenes de Lamberto ${ }^{95}$ y aceptaron la observancia cisterciense, en la línea de Morimond ${ }^{96}$.

Para que la nueva etapa resultase lo más segura y fecunda posible, la abadía cuenta pronto con el apoyo de sus protectores. En 1182 el abad de Santa Maria de Montes de Oca, Romeo, por mediación de Diego Jiménez, vende a Lamberto una heredad en Villamediana ${ }^{97}$; el propio Diego Jiménez le entrega la iglesia de San Bartolomé de Sierra Alba, en Tudelilla ${ }^{98}$; el monarca Alfonso VIII dona tres sernas en Ocón ${ }^{99}$. Del mismo modo, el monasterio recibe unos collazos en Munilla ${ }^{100}$; un cañar junto al río Ebro ${ }^{101}$; unas casas con su corral en Logroño, junto a la iglesia de La Redonda ${ }^{102}$; una heredad en el término de San Pedro ${ }^{103}$; y una heredad en Lasanta ${ }^{104}$.

El cambio de observancia por una parte y la estabilidad política por otra van a ser los determinantes que favorezcan la consecución de una progresiva independencia monástica con respecto a sus protectores. El primer paso se va a dar en 1182. Este año la condesa Endulcia, madre de Diego Jiménez, dona al Cister y al propio monasterio su parte correspondiente en dicha casa ${ }^{105}$, aunque habrá que esperar hasta 1203 para que Rodrigo Díaz, hijo de Diego Jiménez, señor de los Cameros, done el monasterio a la orden del Cister y lo coloque bajo protección real ${ }^{106}$.

Alcanzada su autonomía, la comunidad intenta salvaguardar sus propiedades y sus derechos. En primer lugar recurre al rey: Alfonso VIII libera a sus monjes de todo tributo y concede a sus ganados libertad de pastos en todos sus reinos ${ }^{107}$. Más tarde será el papa quien corrobore

95 G. CoRonel, Historia, fol. 84v.

96 A. Masoliver, "Los cistercienses en España y Portugal», Apéndice de la obra de L. J. LEKAI, Los cistercienses. Ideales y realidad. Barcelona 1987, págs. 521 y 522.

${ }_{97}$ G. Turza, San Prudencio, núm. 47. La amistad entre el abad Romeo y Diego Jiménez vendría motivada por la presencia constante de éste en tierras cercanas a Burgos, donde poseía varios castillos y poblaciones.

${ }_{98}$ Ibidem, núm. 48.

99 Ibidem, núm. 50.

${ }^{100}$ Ibidem, núm. 53.

101 lbidem.

102 Ibidem, núm. 54.

${ }^{103}$ Ibidem, núm. 55.

104 Ibidem, núm. 56.

105 Ibidem, núm. 49.

106 Jbidem, núm. 57.

107 Ibidem, núm. 58. 
sus pertenencias: en 1208, siendo abad Menari, el papa Inocencio III confirma todas. sus posesiones, le concede importantes exenciones y prescribe ciertos estatutos para su gobierno ${ }^{108}$.

Mientras en la tenencia de Calahorra se sucedieron un importante número de personajes ${ }^{109}$, siempre designados por el monarca, al frente del señorio de los Cameros hallamos a una sola familia, cuyos miembros se transmiten el cargo hereditariamente, lo que aprovecha la abadía de San Prudencio para, de su mano, desarrollar un nada desdeñable dominio.

Desde mediados del siglo XI, los señores de los Cameros se convierten en los auténticos dominadores del monasterio; no obstante, el abad sigue desempeñando, como había ocurrido en anteriores etapas de la vida de San Prudencio, un papel fundamental y de primer orden, en aras al funcionamiento de la estructura monástica.

Sus facultades eran a la vez de carácter espiritual y temporal. Frecuentemente ambas se verían recortadas por la presencia de los patronos, como sucede en 1181, cuando Diego Jiménez entrega la abadía a la orden del Cister y cambia su abad y congregación ${ }^{110}$. En aspectos materiales, el abad aparece mediatizado por el patrono ${ }^{111}$, pero suele representar a la comunidad en sentencias ${ }^{112}$, en actos jurídicos (como donaciones ${ }^{113}$, ventas ${ }^{114}$, intercambios ${ }^{115}$ y confirmaciones) ${ }^{116}$, en la recepción de privilegios ${ }^{117}$ y acogida de "familiares" ${ }^{118}$, etc.

Otro de los objetivos fundamentales del abad era cubrir las necesidades de la congregación y procurar el engrandecimiento del dominio monástico. Aquí el papel del abad queda relegado a un segundo plano, puesto que el patrón, en un importante número de casos, será el encargado de ir entregando el caudal necesario de bienes para que los monjes

\footnotetext{
108 Ibidem, núm. 59.

109 A. UBieto, Notas sobre los “Tenentes", pág. 231.

110 G. Turza, San Prudencio, núm. 45.

11 lbidem, núms. 10 y 18.

112 Ibidem, núms. 43 y 44.

113 Ibidem, núms. 15, 16, 21, 22 y 16 ejemplos más.

114 Ibidem, núm. 47.

115 Ibidem, núms. 17 y 24.

116 Ibidem, núm. 13.

117 Ibidem, núm. 34.

118 Ibidem, núms. 37, 39 y 40.
} 


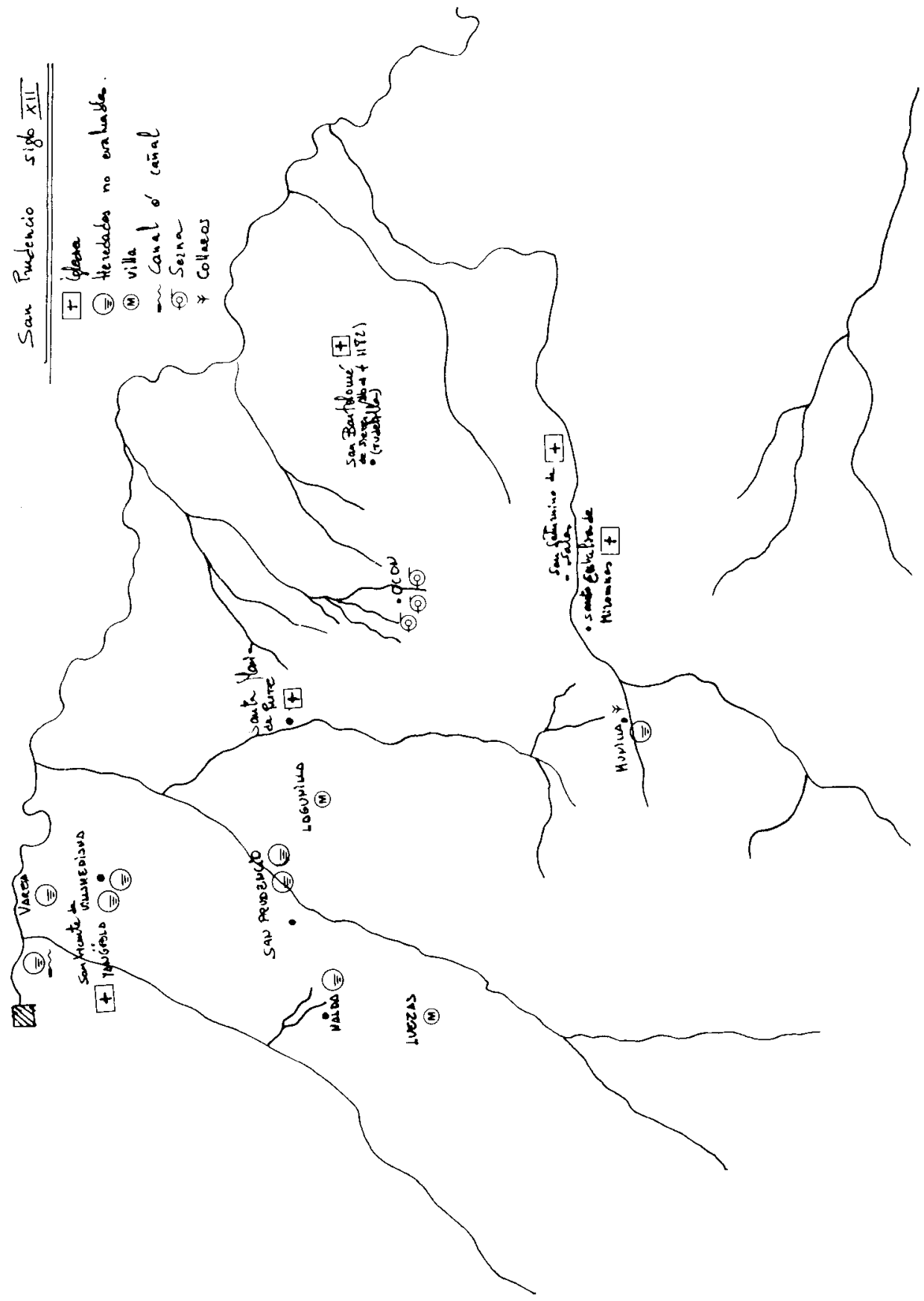


pudieran llevar a cabo sus tareas sin atender a preocupaciones de carácter material.

Nada sabemos de la elección del abad. Muy posiblemente, el patrón ejerciera esta potestad. Por el contrario, tras su nombramiento, el obispo de Calahorra (que nunca podría intervenir en su elección) ${ }^{119}$ le confiere su dignidad, le confirma y le bendice ${ }^{120}$.

A pesar de contar con escasos datos documentales y ante la falta de abadologios completos, para concluir me propongo referir por orden cronológico la relación de abades tanto del monasterio de San Prudencio como los de Santa María de Rute, indicando los años en que aparecen en los testimonios escritos:

\begin{tabular}{|c|c|}
\hline \multirow{2}{*}{\multicolumn{2}{|c|}{$\begin{array}{l}\text { SAN PRUDENCIO } \\
\text { Martin, } 1067-1097\end{array}$}} \\
\hline & \\
\hline \multicolumn{2}{|l|}{ Guillermo, $1120-1121$} \\
\hline \multicolumn{2}{|l|}{ Martín, 1145} \\
\hline Vela * & Raimundo, $1165-1075$ \\
\hline \multicolumn{2}{|l|}{ Domingo * } \\
\hline \multicolumn{2}{|l|}{ Sancho* } \\
\hline \multicolumn{2}{|l|}{ Íñigo * 121} \\
\hline & Lamberto, 1175-1181 \\
\hline \multicolumn{2}{|l|}{ Lamberto, $1181-1184$} \\
\hline \multicolumn{2}{|l|}{ Bernardo, 1196-1198 } \\
\hline Menaro, 1208 & \\
\hline
\end{tabular}

\section{CONCLUSIONES}

1) Recuperada La Rioja, el monasterio de San Prudencio surge, hacia el año 925, como consecuencia de los impulsos repobladores efectuados por los monarcas Sancho Garcés y Ordoño Il y con el fin último de cristianizar y reorganizar el valle de Leza.

119 Ibidem, núm. 59.

120 Ibidem, núm. 29.

121 * Añade A. YePES (Crónica General, II, pág. 325). 
2) En 950 la situación fronteriza frente a los musulmanes obliga a la congregación a buscar protección en la abadía benedictina de San Martín de Albelda, aunque San Prudencio nunca llegó a abandonarse.

3) Fruto de la conquista y repoblación de La Rioja, surge, entre otros, el señorío de los Cameros, linaje que se convierte a partir de 1058 en protector del monasterio, y al que concede todos los bienes necesarios: primero, para ampliar sus tareas religiosas y sociales en el valle del río Leza y, después, para iniciarlas en el espacio geográfico que comprende este río, el Jubera y Cidacos.

4) Como resultado de las luchas suscitadas entre Navarra y Castilla bajo la minoría de Alfonso VIII, y en un momento en que San Prudencio vivía un claro retroceso, el señorio de los Cameros funda un monasterio cisterciense en las cercanías de Ventas Blancas en 1162, denominado Santa María de Rute, que será el encargado de castellanizar su área de influencia.

5) Resuelto el problema fronterizo, los monjes rutenses se trasladan a San Prudencio, donde establecen la obsenancia cisterciense en 1181.

6) A partir de este momento, los patronos procurarán la independencia del monasterio entregando a los monjes sus propias particiones, hasta lograr su total autonomía en 1203. 